\title{
Study of Municipal Sludge Ash as a Brick Material -A Review
}

\author{
M. Jagadeshwaran ${ }^{1 *}$, K. Vijaya Sundravel ${ }^{2}$ \\ ${ }^{1}$ PG Student, Department of Civil Engineering, K.S.Rangasamy College of Technology, Namakkal, Tamil Nadu, \\ India. \\ ${ }^{2}$ Assistant Professor, Department of Civil Engineering, K.S.Rangasamy College of Technology, Namakkal, Tamil \\ Nadu, India. \\ *Corresponding author E-Mail ID: jagadeshcivil.m95@gmail.com \\ Doi: https://doi.org/10.34256/irjmtcon57
}

\begin{abstract}
The municipalities produce sludge of different quality and in different quantities. Sludge resulting from municipalities creates problems of disposal. Generally, dewatered sludge's are disposed of by spreading on the land or by land filling. However, for highly urbanized cities, sludge disposal by land filling might not be appropriate due to land limitation. Incineration might be an alternative solution. However, a substantial amount of ash will be produced after the burning process and must be disposed of by other means. This paper presents the results of the utilization of sludge ash as brick making materials. The different engineering properties were also studied by conducting tests on brick specimens of various mix proportions prepared. It was seen that when percentage of sludge was increased, water requirement as well as water absorption of the bricks increased. But at the same time, compressive strength of the brick decreased. But on addition of cement and fly ash the compressive strength increased and the properties of the bricks improved. Further it can be added that other alternatives like sisal fibres, charcoal husk, lime whose addition shall enhance the properties which can be considered as the scope for future research.
\end{abstract}

Keywords: Municipal Sludge Ash, Incineration, Land Filling.

\section{INTRODUCTION}

In the past few years, we are using the brick which was manufactured by using the clay soil and now-a-days the production of brick including rubber, limestone dust, wood sawdust, fly ash and sludge was taking place. The project has been chosen to improve the strength of the brick by adding the sugarcane bagasse.

\section{NEED OF THE PROJECT}

- To use the alternate raw material in the bricks instead of using clay soil.

- To reduce the demand for clay soil.

- To increase the strength of bricks greater than the normal bricks.

- Producing the light weight bricks

- To reduce the cost of manufacturing of bricks

- To save the natural resources for the future generation use that available in the earth. 
- To use the waste the material that is available in our area (sugarcane factory).

- To develop the eco-friendly construction in our

\section{OBJECTIVES}

- The objective of this project investigation is to improve the production of bricks using sugarcane bagasse fiber.

- To study of the characteristics of sugarcane bagasse fiber.

- To produce economical bricks instead of ordinary brick production.

- To find the compressive strength, water absorption, efflorescence test.

\section{SCOPE OF THE PROJECT}

- We can use bagasse in another type of use in our field to reduce the cost.

- So we suggest that this material can be utilized as a building material.

- Strength should be attained.

- Inspiring and innovative material should be used.

- Excellent properties within both acid and salt environments.

\section{REVIEW OF LITERATURE}

Mangesh V.Madurwar ,Sachin (2017) The major pollution problems faced by smallscale process industries are due to the huge amount of solid and sludge waste generation and the limited treatment facilities. The use of waste as the brick material is a sustainable solution to solid waste management; it provides alternative raw material and an additional source of revenue. The raw materials used here are otherwise landfilled and thus add to ever escalating cost of disposal. The burnt sugarcane bagasse residue is commonly known as SBA. The potential production capacity of burnt sugarcane bagasse residue is around $7-8 \%$ of total bagasse consumed 23,24 . The resulting $\mathrm{CO} 2$ emissions from bagasse are equal to the amount of $\mathrm{CO} 2$ that the sugarcane absorbs from the atmosphere during its growing phase, which makes the process of co-generation greenhouse gas neutral.

Patrick Khaoya Barasa1 (2003) Bagasse is the fibrous residue generated after the juice has been extracted from the sugar cane plant and normally deposited as waste and it litters the environment. Most of the bagasse produced, amounting to one-third of all the cane crushed in some cases supplies the fuel for the generation of steam (Bilba et. al., 2003) which eventually results in bagasse ash. The resulting ash is deposited in stockpiles which are normally dumped in waste landfills and constitute environmental problems to the society. When bagasse is left in the open, it ferments and decays; this brings about the need for safe disposal of the pollutant, which when inhaled in large doses can result in respiratory disease known as bagassiosis.

Osama A. Muhieldeen (2015) Investigate the effects of adding bagasse, cattle manure and sand 5n some physical and chemical properties of the soil and production of Sunflower. Each of the treatment was applied at a rate of 0,30, 45 and 75 than in a RCBD with three replications. The study showed that increasing the rate of the bagasse and cattle manure resulted in a highly significant reduction in soil bulk density, but the addition of sand resulted in increasing the bulk density. Also it was found that porosity was increased highly significant when adding bagasse and cattle manure, and a highly significant reduction in porosity when adding sand to the soil. Bagasse was most effective in reducing bulk density followed by cattle manure and sand. The study 
showed that increasing the rates of addition of each treatment resulted in small increment in exchangeable potassium, total soil nitrogen and phosphorous.

RICHAIiD C. illELENZ (2016) Clays are important to the designer and the construction engineer because their structures frequently rest upon clayey formations, excavations commonly must be made into clayey materials, vast quantities of earth materials containing clays are used in embankments and linings, and clays occur commonly as constituents of engineering materials such as aggregate, pozzolan, and grout. Moreover, clays present many unique problems to the engineer primarily because their physical and chemical instability renders masses of earth susceptible to ready and repeated change of form and volume in response to loading or unloading, vibration, and changing moisture content. As though these qualities were not sufficiently annoying, the degree to which clays respond to these actions commonly changes with adsorption of ions or molecules from solution, precipitation interstitially of granular substances, and alteration of internal texture and structure.

Humphrey Danso (2014) The main materials used for the study are sugarcane bagasse fibre and soil. Sugarcane is plant which grows up to $6 \mathrm{~m}$ high and has a diameter up to $6 \mathrm{~cm}$, and the bagasse is the fibrous residue which is obtained from sugarcane processing after extraction of the juice from the cane stalk. In that literature give the below information about our project Soil blocks of $290 \times 140 \times 100 \mathrm{~mm}$ were made with soil and $0 \%, 0.25 \%, 0.5 \%, 0.75 \%$ and $1 \%$ fibre content by mass. The blocks were made with pressure gauge hydraulic block making machine with a constant pressure of 100 bars. The blocks were sun dried.

\section{TESTING OF BRICK}

\section{Compressive strength test}

The crushing affords a basic comparing the quality of bricks but is of little value in determining the strength of a masonry wall since the latter depends primarily on the strength of mortar.

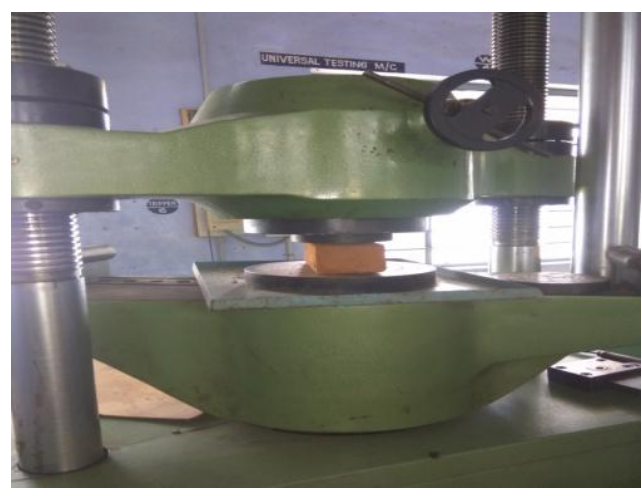

Table of Compressive strength

\begin{tabular}{|c|c|c|c|c|}
\hline S.no & Weight of bagasse(g) & $\begin{array}{c}\text { Sample } 1 \\
(\mathrm{KN})\end{array}$ & $\begin{array}{c}\text { Sample } 2 \\
(\mathrm{KN})\end{array}$ & Average compressive strength $\left(\mathrm{N} / \mathrm{mm}^{2}\right)$ \\
\hline 1 & 0 & 60.50 & 60.40 & 3.055 \\
\hline 2 & 20 & 62.90 & 62.40 & 3.17 \\
\hline 3 & 40 & 65.10 & 64.90 & 3.28 \\
\hline 4 & 60 & 58.32 & 58.10 & 2.94 \\
\hline 5 & 80 & 53.20 & 52.80 & 2.68 \\
\hline 6 & 100 & 42.40 & 40.90 & 2.19 \\
\hline
\end{tabular}


According to IS 1077:1992 (COMMON BURNT CLAY BUILDING BRICKSPECIFICATION) the average compressive strength of building brick is 3-3.5 N/MM². Bricks of high quality do not have strength less than $14 \mathrm{~N} / \mathrm{mm}^{2}$. The strength of the brick is affected by the following factors.

\section{Water Absorption Test}

Water absorption $=\frac{(W 2-W 1)}{W 1} \times 100$

Table of water absorption test

\begin{tabular}{|c|c|c|c|}
\hline Fibre Weight (G) & Weight Before(Kg) & Weight After(Kg) & \% Of Absorption \\
\hline 0 & 2.770 & 3.110 & 12.27 \\
\hline 20 & 2.610 & 2.960 & 13.40 \\
\hline 40 & 2.480 & 2.940 & 18.54 \\
\hline 60 & 2.400 & 2.870 & 19.5 \\
\hline 80 & 2.320 & 2.860 & 23.27 \\
\hline 100 & 2.180 & 2.670 & 22.47 \\
\hline
\end{tabular}

\section{During the water absorption test}

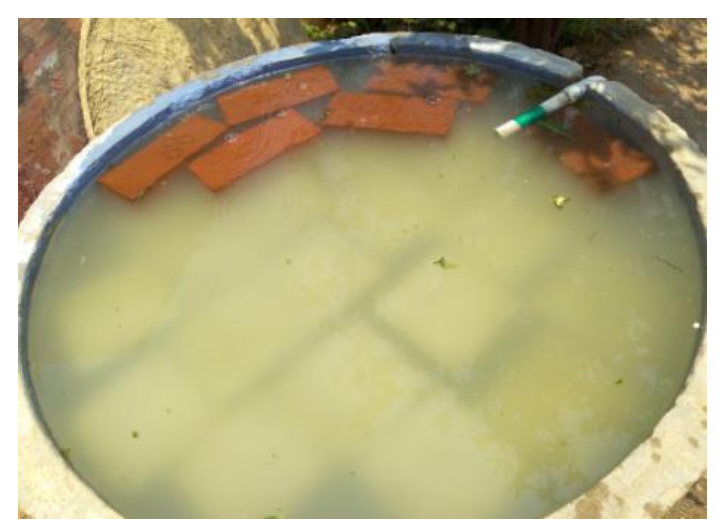

\section{Graph Water absorption test}

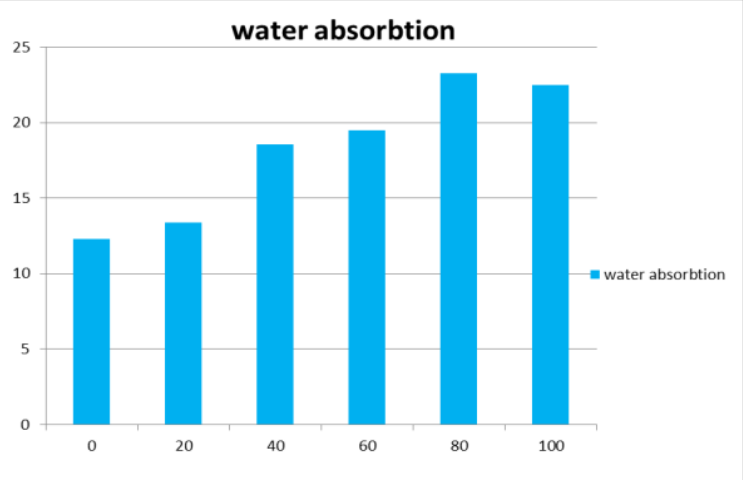




\section{BURNING OF BRICKS}

Burning of brick is achieved either in clamps or in kilns. The clamps are adopted when the bricks are to be manufactured on small scale. If the quality of bricks to be manufactured is large than kiln burning is preferred.

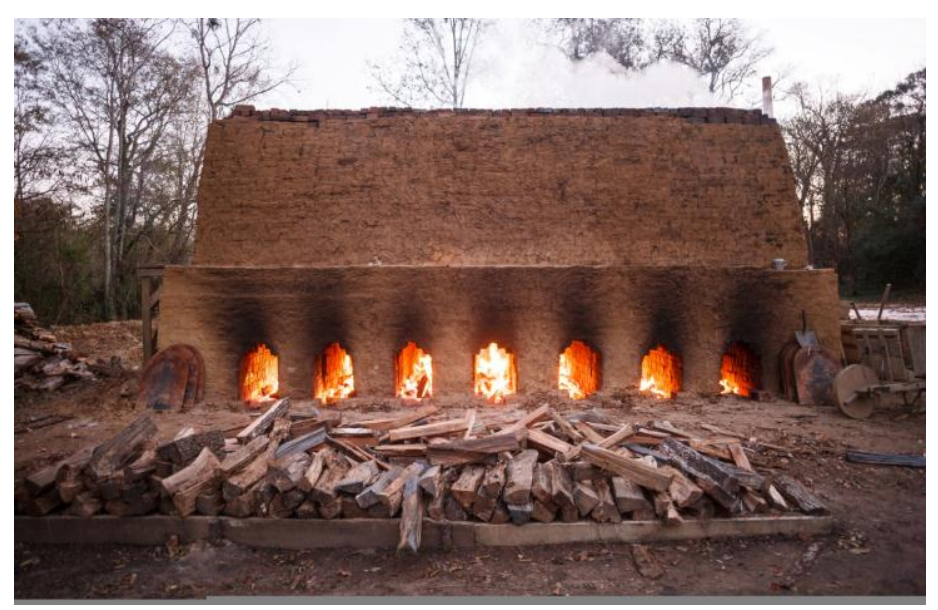

Figure of Burning bricks

\section{CONCLUSION}

- Thus, we conclude by saying that the effective use of sugarcane bagasse waste in brick size of $220 \times 70 \times 90 \mathrm{~mm}$ and casted by hand moulding at replacement of 20,40,60,80,100 grams. The bricks are compared and tested with normal clay bricks.

- The alternate raw material in the bricks instead of using clay soil and bagasse is done successfully. The demand of clay soil is higher so we used the sugarcane bagasse is with the clay soil. Replacement of sugarcane waste brick satisfied the proper properties of quality of good brick. Finally the clay soil bricks are mostly preferred in construction. Hence this is one of the best ways to dispose sugarcane waste.

- The replacement of bagasse fibre brick having compressive strength of $3.05 \mathrm{~N} / \mathrm{mm}^{2}$. The strength of our brick is higher than the normal brick so it can be preferred for the construction works.

\section{REFERENCES}

1. Use of sugarcane bagasse ash as brick Material by Mangesh V.Madurwar ,Sachin ,A. Mandavgane and Rahul V. Ralegaonkar.

2. Stabilization of Expansive Clay Using Lime and Sugarcane Bagasse Ash by Patrick Khaoya Barasa1, Dr. Too, Kiptanui Jonah, S. M. Mulei.

3. Effect Of Sugar Cane Bagasse, Cattle Manure And Sand Addition On Some Physical And Chemical Properties Of The Clay Soils And Sunflower Production In Central Of Sudan by Osama A. Muhieldeen, Elamin. A. Ahmed, Abdelgani M. Shalih.

4. Physical-chemical properties and engineering performance of clays by rlchaiid c. illelenz and ilyrle e. king

5. Effect of sugarcane bagasse fibre on the strength properties of soil blocks by Humphrey Danso, D. Brett Martinson1, Muhammad Ali, John B. Williams

6. Study of fractional restoration of agricultural solid waste in clay and red soil brick by Ganesan.K, Mohamad aslam.A, Mohanraj.N, Prasath.S. 